\title{
MRI AND MOTOR EVOKED POTENTIALS AS A PREDICTOR OF EARLY RECOVERY AFTER ACUTE BRAIN PARENCHYMAL INJURY
}

\author{
Kotakadira Srinivas ${ }^{1}$, Aluka Anand Chand ${ }^{2}$
}

${ }^{1}$ Associate Professor, Department of Neurosurgery, Gandhi Medical College, Secunderabad, Telangana, India.

${ }^{2}$ Assistant Professor, Department of General Surgery, Osmania Medical College, Hyderabad, Telangana, India.

\author{
BACKGROUND \\ ABSTRACT \\ MRI and motor evoked potentials have been widely used in assessment of patient's diagnosis, but their assessment in predicting \\ outcome of acute brain parenchymal injury has been limited. \\ The aim of this study was to measure Motor Evoked Potentials (MEP) intraoperatively and to predict the outcome and early \\ recovery after trauma involving acute brain parenchymal injury.
}

\section{MATERIALS AND METHODS}

A retrospective descriptive study done between 2015 and 2017, at a tertiary trauma care centre, database of 32 patients who have been monitored intraoperatively with motor evoked potentials has been collected. Among them 23 patients came under a, b, c of Association Impairment Scale (AIS). Preoperative and postoperative AIS data, MRI reports, surgical data and use of steroids have been obtained for study. Axial T2 MRI have also been obtained.

\section{RESULTS}

AIS at discharge was significantly predicted by MEP $(p<.001)$. AIS improved by an average of 1.5 grade $($ median= 1$)$ in patients with AIS a, b, c with electable MEPs, while the improvement in those without elicitable MEPs was 0.5 grades (median= $0, \mathrm{p}<.05$ ) MEP status was well correlating with MRI grade.

\section{CONCLUSION}

MEPs predicted neurological improvement in patients with AIS grades $\mathrm{a}, \mathrm{b}$ and $\mathrm{c}$ in patients with acute brain parenchymal injury. MEP prediction was well correlating with MRI grading.

\section{KEY WORDS}

MRI Grading, Acute Brain Parenchymal Injury, Evoked Potentials.

HOW TO CITE THIS ARTICLE: Srinivas K, Chand AA. MRI and motor evoked potentials as a predictor of early recovery after acute brain parenchymal injury. J. Evolution Med. Dent. Sci. 2018;7(44):4713-4716, DOI: 10.14260/jemds/2018/1052

\section{BACKGROUND}

Neurophysiological monitoring in the intraoperative period (IOM) is widely being used with Motor Evoked Potentials (MEP) and Somatosensory Potentials (SSEP) in patients with brain parenchymal injury.(1-2) At present, scientific studies are demonstrating the value of IOM in spinal fusion and deformity, but the use of MEP in acute brain parenchymal injury has been lacking. There is a good amount of literature supporting prognostic value of early neurophysiologic monitoring in preclinical models of acute brain parenchymal injury. There are several studies detailing the use of MEP in intraoperative period in brain surgeries, but they have not given any correlation between MEP and the clinical outcome of the patient after the surgery and their correlation with MRI grade.(2-3) Recent studies have also demonstrated correlation of MEPs with chronic injuries, but did not investigate the role of IOM in acute injury groups.(4-5) The role of intraoperative EEG findings in assessment of future prognosis has also been largely unexplored.

'Financial or Other Competing Interest': None.

Submission 24-09-2018, Peer Review 15-10-2018,

Acceptance 17-10-2018, Published 29-10-2018.

Corresponding Author:

Dr. Kotakadira Srinivas,

Associate Professor, Department of Neurosurgery,

Gandhi Medical College,

Secunderabad, Telangana, India.

E-mail: drkotakadirasrinivas@gmail.com

DOI: $10.14260 /$ jemds/2018/1052

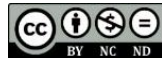

\begin{abstract}
Aims and Objectives
The purpose of this study was: 1) To find correlation of MEPS and clinical examination findings in acute brain parenchymal injury patients; 2) Assessment of role of MEPS as a prognostic marker for acute brain parenchymal injuries; 3) To find correlation between acute magnetic resonance imaging findings and MEPS.
\end{abstract}

\section{MATERIALS AND METHODS}

A retrospective descriptive study was performed to evaluate the diagnostic and prognostic value of MEPS for acute brain parenchymal injury patients admitted to a level 1 trauma centre between January 2015 and December 2017. Patients were identified using a database obtained from Department of Neurosurgery at a level 1 trauma care centre specialised in handling brain parenchymal injuries. We retrospectively identified 131 patients from database with a principal diagnosis of acute brain parenchymal injury. Of them, 32 met inclusion and exclusion criteria.

All of these patients were acute brain parenchymal injuries. Inclusion criteria was set as: (1) Age $\geq 18$, (2) Utilising intraoperative MEPS during surgical decompression and (3) Documented AIS grading at the time of admission before surgery and during follow-up after the surgery. Exclusion criteria was considered to be (1) Cases for which pre-op AIS grading was not mentioned and (2) Cases complicated intraoperatively by hypotension. AIS grading was selected as a measure of neurological outcome based on current guidelines for the classification of brain parenchymal 
injuries.11-13 AIS grades were obtained on all patients included in this study, both at the time of discharge and before the surgery during time of admission.

\section{Intervention Parameters: Imaging Workup and Initial Management}

Twenty-seven patients underwent MRI brain prior to surgery. MRI was performed on a 3 Tesla scanner. 14 axial grading of MRI images was performed with the help of basic (Brain and Spinal injury centre) score. Grading was performed by radiologist who was blinded to the clinical status of the patients. Briefly, based on the most severely affected axial T2 MRI image at the injury epicenter, grades were assigned as follows: Grade 0 injury was defined as no parenchymal signal abnormality, grade 1 injury was defined as T2 hyperintensity approximately confined to the grey matter, grade 2 injury was defined as T2 hyperintensity involving grey and some but not all of the white matter, grade 3 injury was defined as T2 hyperintensity involving both grey and white matter and grade 4 injury was defined as grade 3 injury with the addition of foci of $\mathrm{T} 2$ hypointensity consistent with macroscopic intracerebral haemorrhage. 5 patients were excluded due to non-availability of MRI images prior to decompression surgery. Mean Arterial Pressure (MAP) goal of greater than $85 \mathrm{mmHg}$ was targeted according to our institutional protocol. Earlier high-dose methylprednisolone was used, but later steroids were not used because of deleterious effects.

\section{Intervention Parameters}

All patients taken into consideration for surgery underwent surgical decompression with a total of 32 procedures in 32 patients. IOM including baseline MEP and SSEP were performed on all the patients prior to positioning and surgery

\section{Intervention Parameters: IOM}

Cadwell's cascade elite neuromonitoring equipment for Neurophysiologic monitoring of Transcranial Electrically Stimulated MEPS (TCMEPS), SSEPS and freerunning/evoked electromyography (EMG) were used. Subdermal needle electrodes were placed in Trapezius, Deltoids, Biceps, Triceps, Thenar, Hypothenar and foot flexor/ foot extensor muscles bilaterally for TCMEPS monitoring. Cadwell TCS-1 double train stimulator (pulse with $50 \mathrm{~ms}, 2$ trains of a total of 9 pulses, $1.7 \mathrm{~ms}$ interstimulus, interval $13.1 \mathrm{~ms}$ intertrain interval), constant voltage ranged from 100 to $1000 \mathrm{v}$ was used for stimulation. Subdermal needle electrodes inserted at C1/C2 were used for transcranial stimulation. For EMG activity monitoring, subdermal needle electrodes placed for TCMEPS were used for cerebral monitoring bilaterally. A needle electrode in the right shoulder served as a ground. SSEPS/ TCMEPS/ EMGS were amplified using differential amplifiers, averaged and computer monitored.

Propofol $120 \mathrm{mcg} / \mathrm{kg} / \mathrm{min}$, Fentanyl $100 \mathrm{mcg} / \mathrm{h}$ with Sevoflurane $1.0 \%$ (0.5 MAC) was used as Anaesthesia protocol and a map goal was set as $>85 \mathrm{mmHg}$. Baseline measures for both SSEPS and MEPS were documented while prepositioning. Changes were also documented after position change to prone. Final readings were taken with quantification/ comments on significant changes in
SSEPS/TCMEPS from baseline. Presence or absence of MEPS was verified by two-blinded physicists based on operating room neurophysicist's assessment. MEPS with weak signal were considered present as long as they were reproducible with a constant stimulation voltage.

\section{Statistical Methods}

For statistical analysis one-way ANOVA was used. This is an extension of the Wilcoxon Rank-Sum Test used to compare population location parameters (mean, median etc.) among two or more groups including independent samples. It is based on the ranks of the data and for non-normal data were reported as median (Interquartile Range [IQR]). Means of 2 continuous normally distributed variables were compared by independent samples student's t-test. Mann-Whitney U test were used, respectively, to compare means of 2 and 3 or more groups of variables not normally distributed. Analysis of the data was done using a software SPSS system 16.0.

\section{RESULTS}

57.4 (range 22 - 86 yrs.) is the mean age in the cohort and AIS grades at admission were a $(n=12), b(n=5), c(n=6)$ and $d(n=9)$. Descriptive demographics for this cohort are entered in Table 1 . Of note, approximately 19 of the 32 patients received high-dose methylprednisolone. No clear relationship was found between administration of highdose methylprednisolone and MEPS or AIS recovery. All patients were treated with surgical decompression and stabilisation with intraoperative MEPS.

\begin{tabular}{|c|c|c|c|c|}
\hline $\begin{array}{c}\text { Descriptive } \\
\text { Demographics } \\
\text { Variable }\end{array}$ & $n=32$ & $\begin{array}{c}\text { MEP } \\
\text { Absent } \\
n=13\end{array}$ & $\begin{array}{c}\text { MEP } \\
\text { Present } \\
\text { n=19 }\end{array}$ & $\begin{array}{c}P \\
\text { value }\end{array}$ \\
\hline Male & $26(81.25)$ & 10 & 16 & 0.21 \\
\hline Female & $6(18.75)$ & 3 & 33 & 0.14 \\
\hline Mean age & $\begin{array}{l}57.4 \pm \\
17.65\end{array}$ & $\begin{array}{c}49.5 \pm \\
16.6\end{array}$ & $\begin{array}{c}63.1 \pm \\
16.3\end{array}$ & 0.52 \\
\hline Mean MAP goal & $\begin{array}{c}121.78 \pm \\
41.9\end{array}$ & $\begin{array}{c}135.5 \pm \\
36.4\end{array}$ & $\begin{array}{c}110.59 \pm \\
43.60\end{array}$ & 0.43 \\
\hline Mean ISS score & $\begin{array}{c}22.83 \pm \\
13.27\end{array}$ & $\begin{array}{c}29.7 \pm \\
16.9\end{array}$ & $\begin{array}{c}19.4 \pm \\
9.71\end{array}$ & 0.69 \\
\hline No steroids & 13 & 5 & 11 & 0.26 \\
\hline Mean ICU LOS & $\begin{array}{c}15.42 \pm \\
19.39 \\
\end{array}$ & $\begin{array}{l}26 \pm \\
24.5\end{array}$ & $\begin{array}{c}8.65 \pm \\
5.92\end{array}$ & 0.67 \\
\hline $\begin{array}{c}\text { Mean Hospital } \\
\text { LOS }\end{array}$ & $\begin{array}{c}26.12 \pm \\
26.81\end{array}$ & $\begin{array}{c}33.92 \pm \\
29.9\end{array}$ & $\begin{array}{l}20.90 \pm \\
21.45\end{array}$ & 0.25 \\
\hline Mortality & 1 & 1 & 0 & 0 \\
\hline $\begin{array}{r}\text { Table 1. Des } \\
\text { report }\end{array}$ & 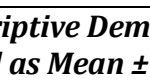 & aphic & $\begin{array}{l}\text { IVari } \\
\text { iation }\end{array}$ & \\
\hline
\end{tabular}

Change of AIS grades from before surgery and after surgery have been entered in Table 2. MEPS significantly predicted the presence of AIS at discharge ( $p<.001$ ). Patients with present intraoperative MEPS had higher AIS grades after surgery in comparison to those subjects with absent MEPS. When looking at the entire patient population (Initial AIS a-d grades), the amount of recovery in AIS grade was not significantly different between patients with absent MEPS in comparison with patients with present MEPS $(\mathrm{p}=158)$. In the group of severe brain parenchyma injury (AIS a, b, c), AIS of patients with elicitable MEPS improved by an average of 1.5 grades (median $=1$ ) as compared to the subjects without elicitable MEP, who on an average only 
improved by 0.5 grades (median=0). No difference was found between the hospital stay between these two groups.

\begin{tabular}{|c|c|c|c|c|}
\hline Variable & $\begin{array}{c}\text { AIS-A } \\
(\mathbf{n = 1 2})\end{array}$ & $\begin{array}{c}\text { AIS-B } \\
(\mathbf{n = 5})\end{array}$ & $\begin{array}{c}\text { AIS-C } \\
(\mathbf{n = 6})\end{array}$ & $\begin{array}{c}\text { AIS-D } \\
(\mathbf{n = 9})\end{array}$ \\
\hline 1 Grade Improvement & 0 & 2 & 5 & 3 \\
\hline 2 Grade Improvement & 3 & 1 & 1 & 0 \\
\hline 3 Grade Improvement & 1 & 0 & 0 & 0 \\
\hline 4 Grade Improvement & 1 & 0 & 0 & 0 \\
\hline $\begin{array}{c}\text { No Improvement/ } \\
\text { Regression }\end{array}$ & 7 & 2 & 0 & 6 \\
\hline
\end{tabular}

Table 2. Incidence of Recovery by Initial AIS Grade

$\mathrm{P}<0.001$

All severe brain parenchyma injury patients (AIS a-c) that had present intraoperative MEPS converted at least 1 AIS grade from before surgery to after surgery. Among those who did not have elicitable intraoperative MEPS $(n=13), 8$ subjects did not show conversion of AIS grades. No significant difference in time to surgery was found for patients with and without MEPS. Patients with absent MEPS had significantly higher basic scores when compared to the patients with present MEPS. All subjects that had a basic score of 4 did not change in their AIS grade before and after surgery.

\section{DISCUSSION}

We have evaluated the prognostic value of IOM in the present study for predicting early neurological recovery after acute brain parenchymal injury.(1-6,7) Results show that presence or absence of intraoperative MEP status is highly predictive of AIS conversion in severe brain parenchymatous injury after the surgery. Further, we found strong electro-radiologic correlation, as intraoperative axial MRI grade (basic score) were found highly correlating with intra-op MEP status. ${ }^{(8,9,10-12)}$

We applied basic score to our subjects and found that patients with positive MEPS were found to have significantly lower basic scores $(\mathrm{p}<.001)$. MEP status was found to be dividing into 2 basic MRI patterns. Patients (80\%) without elicitable MEPS had T2 signal abnormality with both grey matter and white matter (basic 3 and 4) and 94\% patients with preserved MEPS had varying degrees of white or grey matter injuries MRI (basic 0 - 2); 22 in our cohort with intramedullary haemorrhage on axial T2 (basic 4) did not recover. All these patients did not have elicitable MEPS. The use of MEP in brain parenchyma may also provide prognostic value that can guide patient/ family counselling and post-operative treatment. MEPS may even be used to guide medical management. Future studies are required to evaluate the use of MEPS in the intensive care setting.(13-16)

This is a retrospective descriptive study and is subject to the basis inherent with such studies. AIS grades are used rather than international standards for neurological classifications of grading brain parenchymal injury. AIS grades provide less detailed information to evaluate postsurgical changes. Length of stay can be varied for a variety of reasons, many of which are not a reflection of clinical outcomes. Finally, the most compelling finding in this study is the relationship between elicitable MEPS and brain parenchymal injury outcome.(17-19) However, this is limited by a relatively small number of patients $(32$ patients). A prospective study with large sample size is needed to further validate these findings. Even with these limitations, this study has successfully established a relation between MEPS and neurological outcome after acute brain parenchymal injury.(17-19)

\section{CONCLUSION}

Intraoperative elicitation of MEPS is found to be strongly associated with at least partial sparing of brain parenchymal tissue on axial T2 MRI. Future studies regarding role MEPS in the ICU setting should be undertaken and perhaps after establishment of strong relationship, they could even be used to guide medical management. Significant findings like a relationship between MEPS and potential for recovery after surgery for brain parenchymal injury during the acute hospitalisation. The present data needs more evaluation. Prospective studies should be done to further validate these findings.

\section{REFERENCES}

[1] Forbes HJ, Allen PW, Waller CS, et al. Spinal cord monitoring in scoliosis surgery. Experience with 1168 cases. J Bone Joint Surg Br 1991;73(3):487-91.

[2] Nuwer MR, Dawson EG, Carlson LG, et al. Somatosensory evoked potential spinal cord monitoring reduces neurologic deficits after scoliosis surgery: results of a large multicentre survey. Electroencephalogr Clin Neurophysiol 1995;96(1):611.

[3] Park JH, Hyun SJ. Intraoperative neurophysiological monitoring in spinal surgery. World J Clin Cases 2015;3(9):765-73.

[4] Consortium for Spinal Cord Medicine. Early acute management in adults with spinal cord injury: a clinical practice guideline for health-care professionals. J Spinal Cord Med 2008;31(4):403-79.

[5] Fehlings MG, Tator CH, Linden RD. The relationships among the severity of spinal cord injury, motor and somatosensory evoked potentials and spinal cord blood flow. Electroencephalogr Clin Neurophysiol 1989;74(4):241-59.

[6] Thirumala P, Zhou J, Krishnan R, et al. Diagnostic accuracy of evoked potentials for functional impairment after contusive spinal cord injury in adult rats. J Clin Neurosci 2016;25:122-6.

[7] Davey NJ, Smith HC, Savic G, et al. Comparison of input-output patterns in the corticospinal system of normal subjects and incomplete spinal cord injured patients. Exp Brain Res 1999;127(4):382-90.

[8] Curt A, Keck ME, Dietz V. Functional outcome following spinal cord injury: significance of motorevoked potentials and ASIA scores. Arch Phys Med Rehabil 1998;79(1):81-6.

[9] Costa P, Faccani G, Sala F, et al. Neurophysiological assessment of the injured spinal cord: an intraoperative approach. Spinal Cord 2014;52(10):749-57.

[10] Wilson JR, Grossman RG, Frankowski RF, et al. A clinical prediction model for long-term functional outcome after traumatic spinal cord injury based on acute clinical and imaging factors. J Neurotrauma 2012;29(13):2263-71. 
[11] Talbott JF, Whetstone WD, Readdy WJ, et al. The Brain and Spinal Injury Center score: a novel, simple and reproducible method for assessing the severity of acute cervical spinal cord injury with axial T2weighted MRI findings. J Neurosurg Spine 2015;23(4):495-504.

[12] Ryken TC, Hurlbert RJ, Hadley MN, et al. The acute cardiopulmonary management of patients with cervical spinal cord injuries. Neurosurgery 2013;72(Suppl 2):84-92.

[13] Hurlbert RJ, Hadley MN, Walters BC, et al. Pharmacological therapy for acute spinal cord injury. Neurosurgery 2013;72(Suppl 2):93-105.

[14] Calancie B, Klose KJ, Baier S, et al. Isoflurane-induced attenuation of motor evoked potentials caused by electrical motor cortex stimulation during surgery. J Neurosurg 1991;74(6):897-904.

[15] Mabray MC, Talbott JF, Whetstone WD, et al. Multidimensional analysis of MRI predicts early impairment in thoracic and thoracolumbar spinal cord injury. J Neurotrauma 2016;33(10):954-62.
[16] Tsirikos AI, Aderinto J, Tucker SK, et al. Spinal cord monitoring using intraoperative somatosensory evoked potentials for spinal trauma. J Spinal Disord Tech 2004;17(5):385-94.

[17] Castellon AT, Meves R, Avanzi O. Intraoperative neurophysiologic spinal cord monitoring in thoracolumbar burst fractures. Spine 2009;34(24):2662-8.

[18] Flanders AE, Spettell CM, Tartaglino LM, et al. Forecasting motor recovery after cervical spinal cord injury: value of MR imaging. Radiology 1996;201(3):649-55.

[19] Bozzo A, Marcoux J, Radhakrishna M, et al. The role of magnetic resonance imaging in the management of acute spinal cord injury. J Neurotrauma 2011;28(8):1401-11. 